\title{
Modeling preoperative risk factors for potentially lethal morbidities using a nationwide Japanese web-based database of patients undergoing distal gastrectomy for gastric cancer
}

\author{
Chikara Kunisaki $^{1,5} \cdot$ Hiroaki Miyata ${ }^{2,4} \cdot$ Hiroyuki Konno ${ }^{1,2} \cdot$ Zenichiro Saze $^{1}$. \\ Norimichi Hirahara $^{2,4}$ - Hirotoshi Kikuchi ${ }^{1}$ Go Wakabayashi ${ }^{1,2}$.

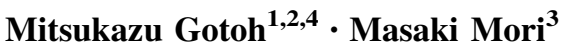

Received: 29 March 2016/ Accepted: 8 August 2016/Published online: 23 August 2016

(c) The International Gastric Cancer Association and The Japanese Gastric Cancer Association 2016

\begin{abstract}
Background Most risk models for mortality and morbidity after distal gastrectomy have been created based on relatively small retrospective studies, and a model originating from nationwide database has been lacking. This study aimed to identify preoperative risk factors that predict the postoperative morbidities closely associated with mortality in gastric cancer patients undergoing distal gastrectomy, using data from the National Clinical Database (NCD), a nationwide web-based database in Japan.

Methods We analyzed records from the NCD for 65,906 patients who underwent distal gastrectomy in 1,986 hospitals during 2011 and 2012. Using $80 \%$ of these patients, we identified independent preoperative predictors for morbidities closely related with mortality. These risk factors were then validated using the remaining $20 \%$ of patients from 2011 to 2012 and the further 35,575 records from 2013.
\end{abstract}

Electronic supplementary material The online version of this article (doi:10.1007/s10120-016-0634-0) contains supplementary material, which is available to authorized users.

Chikara Kunisaki

s0714@med.yokohama-cu.ac.jp

1 The Japanese Society of Gastroenterological Surgery, Working Group Database Committee, Tokyo, Japan

2 The Japanese Society of Gastroenterological Surgery, Database Committee, Tokyo, Japan

3 The Japanese Society of Gastroenterological Surgery, Tokyo, Japan

4 National Clinical Database, Tokyo, Japan

5 Department of Surgery, Gastroenterological Center, Yokohama City University, 4-57 Urafune-cho, Minami-ku, Yokohama 232-0024, Japan
Results Operative mortality was $1.07 \%$ and overall morbidity was $14.2 \%$ for the development data set. We selected eight morbidities that were closely associated with postoperative mortality, and then identified between 13 and 25 independent preoperative risk factors for each of the eight morbidities. Of these, old age, female gender, and poor ADL were the factors most frequently associated with the morbidities. The $\mathrm{C}$-indices for each morbidity from the 2011 to 2012 validation data set were favorable as follows: unplanned intubation (0.797), pneumonia (0.784), systemic sepsis (0.748), renal failure (0.832), cardiac events (0.728), large blood transfusions (0.700), central nervous system (CNS) events (0.779), and anastomotic leakage (0.658). Similar C-indices were obtained for each mortality using the 2013 validation data set.

Conclusions In this study, we successfully constructed an acceptable risk model using preoperative risk factors to predict eight postoperative morbidities highly associated with mortality in gastric cancer patients. This risk model could help to tailor perioperative management and improve clinical outcomes for patients who undergo distal gastrectomy.

Keywords Gastric cancer - Distal gastrectomy · Morbidity $\cdot$ Mortality $\cdot$ Japanese National Clinical Database

\section{Introduction}

Although the incidence of gastric cancer has been decreasing, it remains the third most common cause of cancer-related death worldwide [1]. Gastrectomy with lymph node dissection constitutes the most essential component of multimodality treatment for patients with 
Table 1 Surgical outcomes after distal gastrectomy for 65,906 patients from the 2011 to 2012 National Clinical Database (NCD) data

\begin{tabular}{|c|c|c|c|c|c|c|}
\hline Variable & $\begin{array}{l}\text { No. of } \\
\text { deaths }\end{array}$ & $\begin{array}{l}\text { Total no. of } \\
\text { events }\end{array}$ & $\begin{array}{l}\text { Deaths/total no. } \\
\text { of events }\end{array}$ & $\begin{array}{l}\text { Total no. of } \\
\text { events/total } \\
\text { no. of cases }\end{array}$ & $\begin{array}{l}\text { Pearson's correlation } \\
\text { coefficient with } \\
\text { operative mortality }\end{array}$ & $p$ value \\
\hline \multicolumn{7}{|l|}{ Mortality } \\
\hline 30-day mortality & 297 & 297 & 1.000 & 0.005 & 0.648 & $<0.001$ \\
\hline Operative mortality & 685 & 685 & 1.000 & 0.010 & 1 & $<0.001$ \\
\hline \multicolumn{7}{|l|}{ Morbidity } \\
\hline \multicolumn{7}{|l|}{ General } \\
\hline Any complication & 516 & 9341 & 0.055 & 0.142 & 0.176 & $<0.001$ \\
\hline Repeat surgery & 163 & 1585 & 0.103 & 0.024 & 0.141 & $<0.001$ \\
\hline Any transfusion & 192 & 1089 & 0.176 & 0.017 & 0.209 & $<0.001$ \\
\hline Transfusion $>5 \mathrm{U}^{\mathrm{a}}$ & 130 & 404 & 0.322 & 0.006 & 0.238 & $<0.001$ \\
\hline \multicolumn{7}{|l|}{ Infections } \\
\hline Any systemic sepsis ${ }^{\mathrm{a}}$ & 215 & 868 & 0.248 & 0.013 & 0.266 & $<0.001$ \\
\hline Septic shock & 136 & 243 & 0.560 & 0.004 & 0.325 & $<0.001$ \\
\hline Sepsis & 37 & 241 & 0.154 & 0.004 & 0.084 & $<0.001$ \\
\hline SIRS & 42 & 384 & 0.109 & 0.006 & 0.073 & $<0.001$ \\
\hline \multicolumn{7}{|l|}{ Wound-related } \\
\hline Any SSI & 152 & 2743 & 0.055 & 0.042 & 0.091 & $<0.001$ \\
\hline Superficial SSI & 82 & 1295 & 0.063 & 0.020 & 0.072 & $<0.001$ \\
\hline Deep SSI & 58 & 498 & 0.116 & 0.008 & 0.090 & $<0.001$ \\
\hline Organ space SSI & 122 & 1669 & 0.073 & 0.025 & 0.098 & $<0.001$ \\
\hline Wound dehiscence & 54 & 323 & 0.167 & 0.005 & 0.107 & $<0.001$ \\
\hline \multicolumn{7}{|l|}{ Anastomosis-related } \\
\hline Anastomotic leakage $^{\mathrm{a}}$ & 135 & 1356 & 0.100 & 0.021 & 0.125 & $<0.001$ \\
\hline Pancreatic fistula grade $\mathrm{ABC}$ & 45 & 1051 & 0.043 & 0.016 & 0.040 & $<0.001$ \\
\hline Bile leakage & 23 & 174 & 0.132 & 0.003 & 0.061 & $<0.001$ \\
\hline \multicolumn{7}{|l|}{ Cerebrovascular events } \\
\hline Any CNS event ${ }^{\mathrm{a}}$ & 115 & 311 & 0.370 & 0.005 & 0.241 & $<0.001$ \\
\hline \multicolumn{7}{|l|}{ Respiratory events } \\
\hline Pneumonia $^{\mathrm{a}}$ & 221 & 1331 & 0.166 & 0.020 & 0.217 & $<0.001$ \\
\hline Unplanned intubation $^{\mathrm{a}}$ & 228 & 511 & 0.446 & 0.008 & 0.374 & $<0.001$ \\
\hline Prolonged ventilation $>48 \mathrm{~h}$ & 223 & 522 & 0.427 & 0.008 & 0.362 & $<0.001$ \\
\hline \multicolumn{7}{|l|}{ Cardiac events } \\
\hline Any cardiac event ${ }^{\mathrm{a}}$ & 134 & 183 & 0.732 & 0.003 & 0.370 & $<0.001$ \\
\hline Pulmonary embolism & 8 & 55 & 0.145 & 0.001 & 0.038 & $<0.001$ \\
\hline \multicolumn{7}{|l|}{ Urinary tract events } \\
\hline Renal failure ${ }^{\mathrm{a}}$ & 168 & 441 & 0.381 & 0.007 & 0.296 & $<0.001$ \\
\hline Acute renal failure & 95 & 168 & 0.565 & 0.003 & 0.273 & $<0.001$ \\
\hline Urinary tract infection & 26 & 283 & 0.092 & 0.004 & 0.052 & $<0.001$ \\
\hline
\end{tabular}

SIRS systemic inflammatory response syndrome, SSI surgical site infection, CNS central nervous system

a Selected to create the risk models

resectable gastric cancer [2]. Although distal gastrectomy with D2 lymph node dissection is a common procedure in Japan [3], we still encounter postoperative morbidities that could lead to mortality. With progressive aging of the Japanese population, an increasing number of elderly patients with a variety of preoperative comorbidities become candidates for surgical treatment [16]. Managing these patients adequately to avoid postoperative morbidity is essential to improve surgical outcomes after gastrectomy, and identification and prediction of potentially lethal postoperative morbidities is mandatory for that purpose.

Many studies have carried out risk stratifications for morbidities such as anastomotic leakage $[4,5]$, renal failure $[6,7]$, pneumonia [8-10], systemic inflammatory responses 
[11], and unplanned intubation [12], among others [13-15]. Although these reports often analyzed a single morbidity, occurrence of one postsurgical complication may lead to others, and mortality sometimes occurs as a combined result of two or more complications. Precise association of each of these morbidities with mortality has not been evaluated, probably because only small numbers of patients have been available from the database used in single institution studies. For that matter, even the data set available from the ACS-NSQIP has been considered insufficient $[14,15]$.

More recently, a risk model to predict 30-day mortality (death within 30 days after surgery, whether in or out of hospital) and operative mortality (death within the hospitalization period up to 90 days) was constructed using data from the National Clinical Database (NCD), a nationwide web-based database covering 33,917 patients who underwent distal gastrectomy in Japan in 2011. In the process of creating that model, 17 and 21 preoperative risk factors that predict 30-day and operative mortalities after distal gastrectomy, respectively, were identified [17]. For more precise management of the patients, we conducted the current study using the NCD data to first identify postoperative morbidities that are closely associated with mortality and then find preoperative risk factors that are predictive of these morbidities to ultimately create risk models for prediction of potentially lethal morbidities.

\section{Methods}

\section{Data collection}

The NCD in Japan, which commenced patient registration in January 2011, is a nationwide project linked to the surgical board certification system [18, 19]. Submitting cases to the NCD is a prerequisite for all institutions associated with either or both the Japan Surgical Society and the Japanese Society of Gastroenterological Surgery, and only registered cases can be counted among the number of surgeries conducted by a surgeon to be accredited the board-certified surgeon. To assure the traceability of data, the NCD continuously tracks the surgeons who approve data, other medical staff who supervise departmental caseloads, and the administrative staff who are responsible for data entry through its web-based data management system. The variables recorded by the NCD are almost identical to those used by the ACS-NSQIP (http://site. acsnsqip.org/wp-content/uploads/2013/10/ACSNSQIP.PUF_. UserGuide. 2012. pdf\#search $=$ "user + guide + for + the $+2012+$ ACS+NSQIP). The independent variables available for this study include patient demographics, preexisting comorbidities, preoperative laboratory results, and perioperative data.

\section{Study population}

From the patients who underwent distal gastrectomy for gastric cancer at 1986 institutions throughout Japan between January 1, 2011 and December 31, 2012, 3,837 patients who had undergone any associated organ resection with the exception of cholecystectomy were excluded, and the data of the remaining 65,906 patients were used to develop a risk model. Informed consent to use the clinical data was obtained from each of the patients.

\section{Outcome measures (mortality and postoperative events)}

The postoperative morbidities were classified into the following categories: general (repeat laparotomy, any blood transfusion, blood transfusion $\geq 5$ units red blood cells), infectious [septic shock, severe sepsis, systemic inflammatory response syndrome (SIRS)], wound related [including superficial incisional surgical site infection (SSI), deep incisional SSI, organ/space SSI with or without anastomotic leakage, and wound disruption], anastomosisrelated (anastomotic leakage, pancreatic fistula, bile leakage), central nervous system (CNS) (stroke, coma for $<24 \mathrm{~h}$ ), respiratory (pneumonia, unplanned intubation, ventilation for $>48 \mathrm{~h}$ ), cardiac (cardiac arrest, myocardial infarction, pulmonary embolism), and urinary tract (renal failure, acute renal failure, urinary tract infections). Of these, morbidities with the incidence (total number of events/total number of cases) exceeding $15 \%$ and with more than $15 \%$ operative mortality rate (number of death/total number of events) were selected from each category for further evaluation. If several postoperative morbidities per category fulfilled the criteria, up to two morbidities were selected. In contrast, no morbidity was selected from one category in which none of the morbidities exceeded the mortality of $15 \%$. A stepwise selection method was conducted to identify relevant predictive factors that could be evaluated preoperatively for each of the morbidities to construct a risk model.

\section{Statistical analysis}

We used IBM SPSS Statistics for Windows (Version 20; IBM, Armonk, NY, USA) for data analysis. Univariate analysis of the data was performed using Fisher's exact test, the unpaired Student's $t$ test, and the Mann-Whitney $U$ test. Correlations between each morbidity and operative mortality were analyzed using Pearson product-moment correlation.

Data from the 2011 to 2012 NCD were randomly assigned to two subsets, that is, a development data set, which included 52,770 (80 \%) records, and a validation 


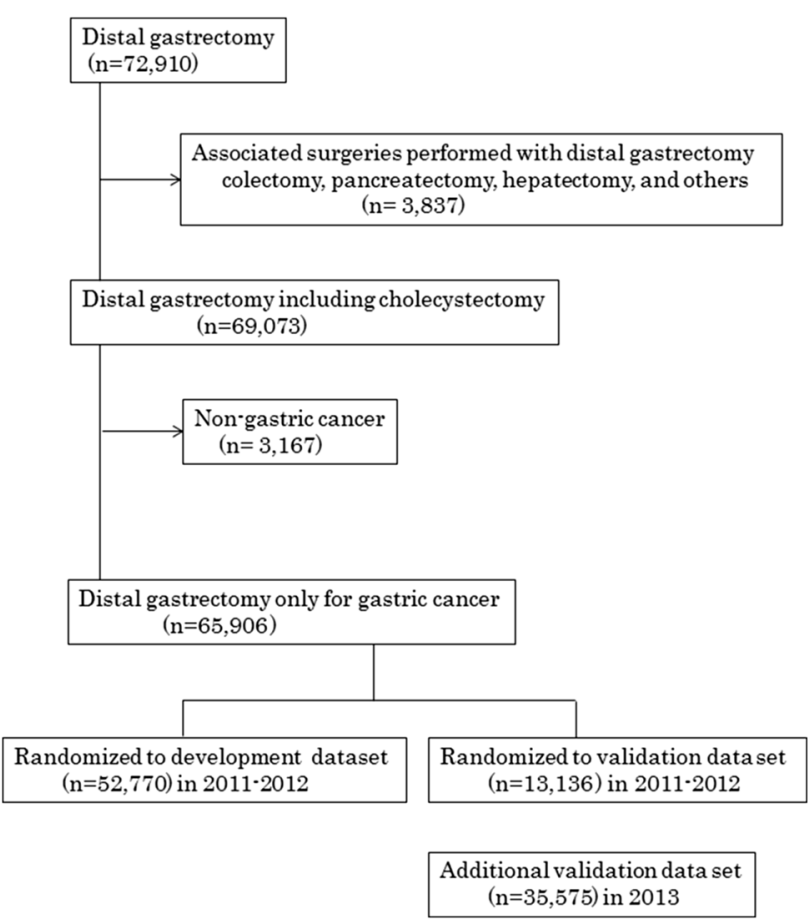

Fig. 1 Selection process for the study population. Single asterisk National Clinical Database (NCD) data from 2011 to 2012, double asterisk NCD data from 2013

data set, which included 13,136 (20\%) records. Logistic regression models were constructed with the development data set using a stepwise selection method in which preoperative risk factors for each morbidity with $p<0.05$ were selected for inclusion. A "goodness-of-fit" test was performed to assess how well the model discriminated between patients with or without morbidities highly related to mortality. Receiver operating characteristic (ROC) curves, which plot the true-positive rate (sensitivity) versus the false-positive rate $(1-$ specificity) of tests, were then created with the validation data set for the eight morbidities, and concordance index (C-index) was calculated for these morbidities to confirm the validity of the models in this study. Further validation was performed with 35,575 records from the 2013 NCD dataset to improve the transparency of this study in accordance with the recent TRIPOD statement [20] (Fig. 1).

\section{Results}

\section{Clinical data for the study population}

The study population had a mean age of 69.1 years; $66.7 \%$ of the population was male, mean body surface area (BSA, $\mathrm{m}^{2}$ ) was $1.58,21.9 \%$ had a body mass index (BMI) greater than $25 \mathrm{~kg} / \mathrm{m}^{2}, 4.8 \%$ had undergone a body weight loss of more than $10 \%$, and $0.9 \%$ were emergency surgery. Regarding activities of daily living (ADL), $4.7 \%$ of the patients needed some level of assistance, and of these, $44 \%$ patients had needed assistance within 30 days of surgery. Of the patients, $9.5 \%$ showed comorbid diseases classified as having an ASA score of 3 or more. A Brinkman index (the number of cigarettes smoked per day multiplied by the number of years of smoking) greater than 400 was observed in $28.7 \%$ of the patients. Frequent comorbidities were hypertension $(34.4 \%)$, diabetes mellitus $(15.7 \%)$, hypoalbuminemia $(15.0 \%)$, liver dysfunction (8.1-8.6\%), and renal dysfunction with serum creatinine levels $\geq 1.2 \mathrm{mg} / \mathrm{ml}(6.8 \%)$. In addition, cerebrovascular disease was observed in $3.7 \%$ of the population, bleeding disorder in $3.4 \%$, previous percutaneous coronary intervention (PCI) in $2.5 \%$, and respiratory disorder in $2.1 \%$. For 65,906 gastric cancer patients during 2011 and 2012, open distal gastrectomy was performed for 41,737 patients and laparoscopic distal gastrectomy for 24,169. Comparison of patient characteristics between these two groups is listed in Supplemental Table 1.

\section{Surgical outcomes after distal gastrectomy}

The 30-day and operative mortalities were $0.45 \%$ (297 deaths) and $1.07 \%$ (704 deaths), respectively. Adverse intraoperative events occurred in 2,269 (3.4\%) patients, $1,228(1.9 \%)$ patients underwent reoperation within 30 days after the surgery, and 1,277 (1.9\%) patients were readmitted within 30 days of the surgery. Postoperative complications occurred in 9,339 (14.2\%) patients. Of these, we identified the following eight morbidities as clinically relevant in terms of incidence and association with mortality: unplanned intubations, pneumonia, any systemic sepsis, renal failure, any cardiac events, blood transfusions over 5 units, cerebrovascular events, and anastomotic leakage (Table 1).

\section{Association of the eight morbidities with other complications and mortality}

In Table 2, Pearson's correlation coefficients $(r)$ were calculated for 30-day and operative mortalities with the eight morbidities. Unplanned intubation was most highly correlated with operative mortality $(r=0.374)$. On the other hand, anastomotic leakage was the most weakly correlated with operative mortality $(r=0.125)$. Unplanned intubation was also highly correlated with other morbidities such as pneumonia $(r=0.357)$, any systemic sepsis $(r=0.355)$, renal failure $(r=0.351)$, cardiac events $(r=0.364)$, and blood transfusion over 5 units $(r=0.328)$, but weakly correlated with anastomotic leakage $(r=0.132)$. By contrast, anastomotic leakage tended 


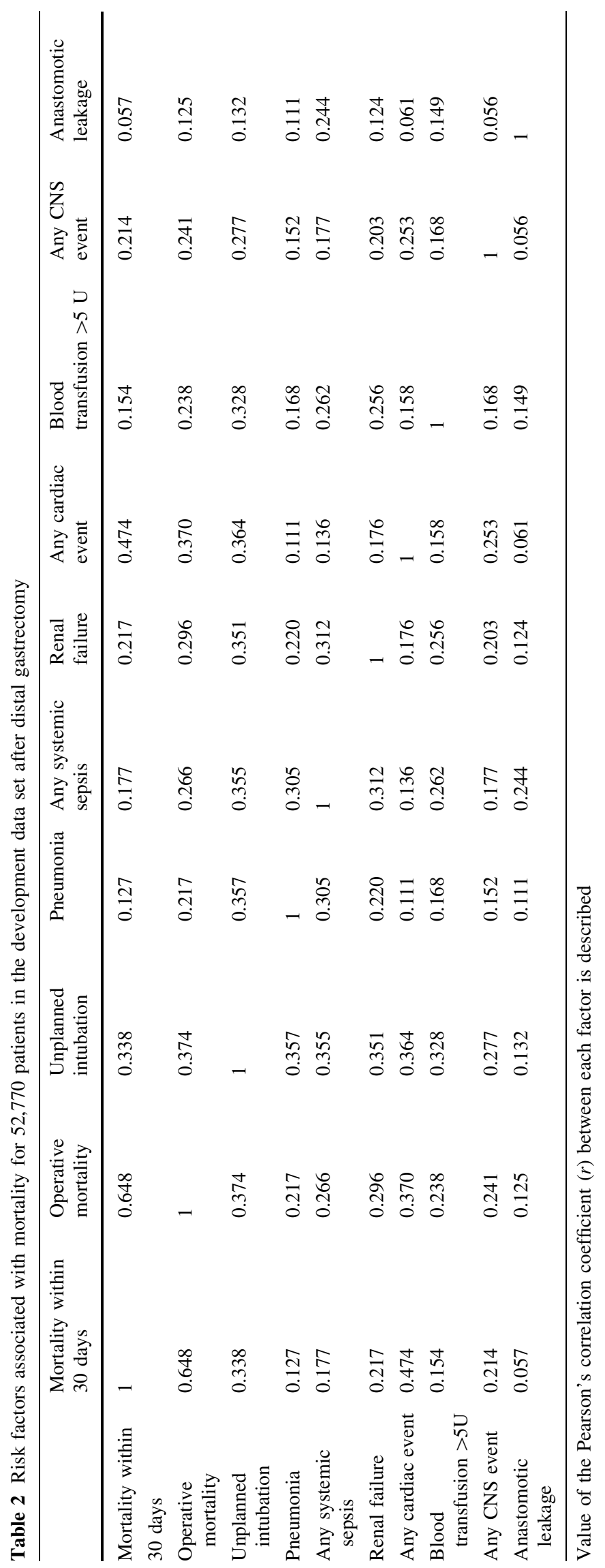


Table 3 Logistic regression analysis for the development data set predicting unplanned intubation, pneumonia, systemic sepsis, and renal failure from preoperative variables

\begin{tabular}{|c|c|c|c|c|}
\hline \multirow[t]{2}{*}{ Variables $^{\mathrm{a}}$} & \multicolumn{4}{|l|}{ Odds ratio $(95 \%$ CI $)$} \\
\hline & Unplanned intubation & Pneumonia & Any systemic sepsis & Renal failure \\
\hline \multicolumn{5}{|l|}{ Demographics } \\
\hline Age & $1.343(1.243-1.451)$ & $1.359(1.295-1.425)$ & $1.107(1.052-1.164)$ & \\
\hline Male gender & $2.152(1.596-2.903)$ & $2.840(2.333-3.458)$ & $1.846(1.514-2.251)$ & $1.874(1.409-2.492)$ \\
\hline \multicolumn{5}{|l|}{ General } \\
\hline Total ADL 30 days before surgery & & $1.961(1.360-2.829)$ & & \\
\hline $\begin{array}{l}\text { Any ADL } \\
\text { before surgery }\end{array}$ & $2.136(1.619-2.818)$ & $2.192(1.814-2.650)$ & $2.070(1.641-2.611)$ & $2.284(1.710-3.052)$ \\
\hline $\mathrm{ASA} \geq$ grade 3 & & & $1.420(1.158-1.740)$ & $1.822(1.406-2.362)$ \\
\hline BMI category & & & $1.293(1.117-1.497)$ & \\
\hline $\mathrm{BMI}>25$ & & $1.321(1.106-1.578)$ & & \\
\hline $\mathrm{BMI}>30$ & $2.403(1.340-4.308)$ & & & $1.935(1.118-3.348)$ \\
\hline $\mathrm{BSA} \times 10$ & $0.929(0.870-0.993)$ & $0.909(0.869-0.952)$ & & \\
\hline Brinkman index $>400$ & & $1.226(1.067-1.408)$ & & \\
\hline Brinkman index > 600 & & & $1.247(1.048-1.485)$ & \\
\hline Smoking within a year & $1.434(1.117-1.841)$ & & & \\
\hline Body weight loss $>10 \%$ & & & $1.596(1.236-2.060)$ & \\
\hline \multicolumn{5}{|l|}{ Respiratory } \\
\hline COPD & $1.602(1.143-2.244)$ & $2.074(1.675-2.568)$ & $1.799(1.380-2.343)$ & \\
\hline Preoperative pneumonia & $2.205(1.237-3.930)$ & $3.074(2.073-4.557)$ & & \\
\hline Any respiratory distress & $2.128(1.490-3.040)$ & $1.840(1.443-2.347)$ & & \\
\hline \multicolumn{5}{|l|}{ Cardiovascular } \\
\hline Hypertension & & $1.280(1.126-1.455)$ & $1.229(1.049-1.440)$ & $1.624(1.291-2.043)$ \\
\hline Congestive & $2.376(1.508-3.744)$ & & $2.620(1.749-3.925)$ & $3.012(1.914-4.741)$ \\
\hline \multicolumn{5}{|l|}{ heart failure } \\
\hline Previous cardiac surgery & $2.793(1.824-4.278)$ & & & \\
\hline Previous PCI & & $1.479(1.138-1.922)$ & & \\
\hline Previous PVD surgery & & & & $3.305(1.904-5.737)$ \\
\hline PVD & $2.092(1.054-4.153)$ & & & \\
\hline \multicolumn{5}{|l|}{ Renal } \\
\hline Acute renal failure & $3.636(0.995-13.295)$ & & & \\
\hline \multicolumn{5}{|l|}{ CNS } \\
\hline Cerebrovascular disease & $1.648(1.195-2.273)$ & & & \\
\hline CVA & & $1.654(1.275-2.145)$ & & \\
\hline \multicolumn{5}{|l|}{ Hematological } \\
\hline Untreated bleeding disorder & & & $1.955(1.079-3.544)$ & \\
\hline Preoperative blood transfusions & & $1.347(1.051-1.726)$ & $1.560(1.158-2.103)$ & \\
\hline \multicolumn{5}{|l|}{ Infections } \\
\hline Systemic sepsis & $5.015(2.252-11.169)$ & $4.303(2.210-8.375)$ & $4.145(1.952-8.799)$ & $5.557(2.264-13.637)$ \\
\hline \multicolumn{5}{|l|}{ Other } \\
\hline Uncontrolled ascites & $2.302(1.413-3.751)$ & $1.824(1.259-2.643)$ & & \\
\hline Any esophageal varices & $2.842(1.311-6.162)$ & & & $5.050(2.502-10191)$ \\
\hline Uncontrolled esophageal varices & & $3.708(1.753-7.844)$ & & \\
\hline Open wound & & & $4.220(0.926-19.222)$ & \\
\hline Preoperative radiotherapy & & & 3.655 (1.256-10.634) & \\
\hline
\end{tabular}


Table 3 continued

\begin{tabular}{|c|c|c|c|c|}
\hline \multirow[t]{2}{*}{ Variables $^{\mathrm{a}}$} & \multicolumn{4}{|l|}{ Odds ratio $(95 \% \mathrm{CI})$} \\
\hline & Unplanned intubation & Pneumonia & Any systemic sepsis & Renal failure \\
\hline \multicolumn{5}{|c|}{ Preoperative laboratory data } \\
\hline $\mathrm{WBC}>11,000$ & $1.865(1.148-3.029)$ & $1.711(1.231-2.378)$ & & \\
\hline PLt $<15$ & $1.374(1.029-1.834)$ & & & \\
\hline ALB $<3.8$ & $1.467(1.173-1.835)$ & & & \\
\hline ALB $<4.0$ & & $1.359(1.182-1.563)$ & $1.388(1.174-1.640)$ & $1.809(1.415-2.314)$ \\
\hline AST $>35$ & $1.531(1.154-2.031)$ & & & \\
\hline AST $>40$ & & & & $1.964(1.394-2.766)$ \\
\hline ALT $>340$ & & & $1.413(1.108-1.800)$ & \\
\hline Cre $>1.2$ & $1.481(1.130-1.941)$ & & $1.278(1.018-1.604)$ & $3.309(2.475-4.424)$ \\
\hline Urea nitrogen $>25$ & & & & $2.184(1.616-2.952)$ \\
\hline $\mathrm{Na}<135$ & $1.506(1.073-2.114)$ & & & \\
\hline $\mathrm{Na}<138$ & & & & $1.412(1.077-1.852)$ \\
\hline $\mathrm{CRP}>1$ & & $1.454(1.225-1.726)$ & & \\
\hline $\mathrm{CRP}>10$ & & & $2.505(1.375-4.565)$ & \\
\hline PT_INR > 1.1 & $1.351(1.052-1.735)$ & & & \\
\hline PT_INR $>1.25$ & & & & $1.671(1.148-2.431)$ \\
\hline $\mathrm{APTT}>40$ & $1.590(1.093-2.313)$ & $1.320(1.002-1.740)$ & $1.504(1.083-2.087)$ & \\
\hline
\end{tabular}

$A D L$ activities of daily living, $A L B$ serum albumin (mg/dl), $A L T$ alanine transaminase (IU/l), APTT activated partial thromboplastin time (s), $A S A$ American Society of Anesthesiologists, $A S T$ aspartate transaminase (IU/l), BMI body mass index $\left(\mathrm{kg} / \mathrm{m}^{2}\right), B S A$ body surface area $\left(\mathrm{m}^{2}\right), C O P D$ chronic obstructive pulmonary disease, Cre creatinine (mg/l), Na natrium (mEq/l), CRP C-reactive protein (mg/dl), CVA cerebrovascular accident, $P C I$ percutaneous coronary intervention, $P L t$ platelets $\left(\times 10^{4} / \mu \mathrm{l}\right), P T-I N R$ prothrombin time-international normalized ratio, $P V D$ peripheral vascular disease, $W B C$ white blood cell count $\left(>10,000 / \mathrm{m}^{3}\right), 95 \% C I 95 \%$ confidence interval

to be weakly correlated with other morbidities with exception of systemic sepsis $(r=0.244)$.

\section{Logistic regression analysis with preoperative risk factors in the development data set}

We performed multivariate logistic regression analysis to identify the preoperative risk factors for the eight postoperative morbidities that were closely associated with operative mortality in the development data set. A variety of preoperative factors were associated with each morbidity: 25 factors with unplanned intubation, 20 with pneumonia, 20 with systemic sepsis, 16 with renal failure, 14 with cardiac events, 22 with blood transfusions of more than 5 units, 14 with CNS events, and 13 with anastomotic leakage (Tables 3, 4).

Common risk factors for most morbidities were older age, male gender, poor ADL, high BMI, cardiovascular disease, and low albumin levels. Of these preoperative risk factors, male gender was associated with eight morbidities, older age with seven morbidities, and poor ADL before surgery with seven morbidities. They were considered as the most important predictive factors.

As for other risk factors, smoking increased the risk of unplanned intubation, pneumonia, systemic sepsis, CNS events, and anastomotic leakage. Respiratory disease increased the risk of unplanned intubation, pneumonia, and systemic sepsis. Cerebrovascular disease increased the risk of CNS events and also unplanned intubation and pneumonia. Bleeding disorders and preoperative transfusions increased the risk of postoperative transfusions, as well as pneumonia, systemic sepsis, and anastomotic leakage. Preoperative systemic sepsis was, unsurprisingly, a risk factor for postoperative morbidities including unplanned intubation, pneumonia, systemic sepsis, renal failure, and cardiac events. The presence of ascites or esophageal varices increased the risk of unplanned intubation, pneumonia, renal failure and postoperative transfusions. Elevated white blood cell count (WBCs) or C-reactive protein (CRP) levels increased the risk of unplanned intubation, pneumonia, cardiac events and postoperative transfusions. Preoperative renal insufficiency increased the risk of postoperative renal failure as well as unplanned intubation, systemic sepsis, and cardiac events.

\section{Model performance}

To evaluate the performance of these models, we used the $\mathrm{C}$-index. The $\mathrm{C}$-indices calculated for the eight selected morbidities after risk analyses of the 2011-2012 validation data set were 0.797 (95\% CI, 0.785-0.837) for unplanned intubation, 0.784 (95\% CI, 0.755-0.813) for pneumonia, 
Table 4 Logistic regression analysis for the development data set predicting cardiac events, blood transfusions over 5 units, CNS events, and anastomotic leakage from preoperative variables

\begin{tabular}{|c|c|c|c|c|}
\hline \multirow[t]{2}{*}{ Variables $^{\mathrm{a}}$} & \multicolumn{4}{|l|}{ Odds ratio $(95 \% \mathrm{CI})$} \\
\hline & Cardiac events & $\begin{array}{l}\text { Blood transfusions } \\
>5 \text { units }\end{array}$ & CNS events & Anastomotic leakage \\
\hline \multicolumn{5}{|l|}{ Demographics } \\
\hline Age & $1.197(1.064-1.346)$ & $1.132(1.045-1.225)$ & $1.279(1.169-1.401)$ & $1.083(1.042-1.125)$ \\
\hline Male gender & $2.451(1.544-3.893)$ & $2.297(1.665-3.167)$ & $1.512(1.086-2.106)$ & $2.110(1.787-2.493)$ \\
\hline \multicolumn{5}{|l|}{ Preoperative risk assessment: general } \\
\hline Total ADL 30 days before surgery & & $1.638(1.159-2.314)$ & & \\
\hline Any ADL before surgery & $1.900(1.198-3.014)$ & & $2.237(1.582-3.161)$ & $1.495(1.183-1.890)$ \\
\hline $\mathrm{ASA} \geq \operatorname{grade} 3$ & $1.699(1.125-2.566)$ & & $1.456(1.062-1.996)$ & $1.233(1.027-1.480)$ \\
\hline \multicolumn{5}{|l|}{ BMI category } \\
\hline $\mathrm{BMI}>25$ & & & & $1.568(1.362-1.805)$ \\
\hline $\mathrm{BMI}>30$ & & $2.636(1.438-4.830)$ & & \\
\hline $\mathrm{BSA} \times 10$ & & $0.904(0.842-0.971)$ & & \\
\hline Brinkman index $>400$ & & & $1.510(1.141-1.998)$ & $1.267(1.110-1.446)$ \\
\hline Body weight loss $>10 \%$ & & & & $1.523(1.205-1.923)$ \\
\hline \multicolumn{5}{|l|}{ Respiratory } \\
\hline COPD & & $1.795(1.212-2.658)$ & & \\
\hline Preoperative pneumonia & $2.967(1.237-7.115)$ & & & \\
\hline \multicolumn{5}{|l|}{ Cardiovascular } \\
\hline Any hypertension & & $1.415(1.118-1.791)$ & & $1.189(1.048-1.352)$ \\
\hline Congestive heart failure & $3.623(1.870-7.021)$ & & $2.026(1.063-3.861)$ & \\
\hline Myocardial infarction & & $2.490(1.276-4.860)$ & $3.158(1.665-5.989)$ & \\
\hline Previous cardiac surgery & & $1.878(1.088-3.240)$ & & \\
\hline Previous PCI & $1.832(1.025-3.276)$ & & & \\
\hline PVD & & & $2.481(1.097-5.611)$ & \\
\hline \multicolumn{5}{|l|}{ CNS } \\
\hline Cerebrovascular disease & & & $3.070(2.181-4.321)$ & \\
\hline \multicolumn{5}{|l|}{ Hematological } \\
\hline Untreated bleeding disorder & & $2.688(1.467-4.925)$ & & \\
\hline Preoperative blood transfusions & & $1.750(1.164-2.631)$ & & $1.430(1.069-1.912)$ \\
\hline \multicolumn{5}{|l|}{ Infections } \\
\hline Systemic sepsis & $4.124(1.179-13.300)$ & & & \\
\hline \multicolumn{5}{|l|}{ Other } \\
\hline Uncontrolled ascites & & $2.172(1.255-3.759)$ & & \\
\hline Esophageal varices & & $4.223(2.184-8.165)$ & & \\
\hline Ambulance transport & $2.382(1.259-4.508)$ & & & \\
\hline \multicolumn{5}{|l|}{ Preoperative laboratory data } \\
\hline WBC $>11,000$ & & $2.212(1.331-3.675)$ & & \\
\hline $\mathrm{WBC}>9,000$ & $1.747(1.048-2.912)$ & & & \\
\hline $\mathrm{HCT}<21$ & & $2.229(1.194-4.160)$ & & \\
\hline $\mathrm{HCT}<37(\widehat{\jmath})$ & $1.584(1.047-2.397)$ & & & \\
\hline \multicolumn{5}{|l|}{$<32($ ( $)$} \\
\hline $\mathrm{PLt}<15$ & & $2.086(1.548-2.811)$ & $1.471(1.024-2.115)$ & \\
\hline $\mathrm{ALB}<2.5$ & & & & $1.654(1.169-2.341)$ \\
\hline ALB $<3.5$ & & $1.525(1.161-2.001)$ & & \\
\hline ALB $<3.8$ & $1.658(1.095-2.512)$ & & $1.779(1.344-2.355)$ & \\
\hline $\mathrm{AST}>40$ & & $1.547(1.094-2.189)$ & & \\
\hline
\end{tabular}


Table 4 continued

\begin{tabular}{|c|c|c|c|c|}
\hline \multirow[t]{2}{*}{ Variables $^{\mathrm{a}}$} & \multicolumn{4}{|l|}{ Odds ratio $(95 \% \mathrm{CI})$} \\
\hline & Cardiac events & $\begin{array}{l}\text { Blood transfusions } \\
>5 \text { units }\end{array}$ & CNS events & Anastomotic leakage \\
\hline $\mathrm{ALT}>35$ & & & & $1.216(1.005-1.472)$ \\
\hline Urea nitrogen $>25$ & & $1.406(1.002-1.973)$ & & \\
\hline $\mathrm{eGFR}<30$ & $1.689(1.046-2.726)$ & & & \\
\hline $\mathrm{Na}<130$ & $3.532(1.622-7.688)$ & & $2.386(1.170-4.865)$ & \\
\hline $\mathrm{CRP}>10$ & & $2.702(1.298-5.626)$ & $4.671(2.306-9.461)$ & $2.380(1.358-4.170)$ \\
\hline PT_INR > 1.1 & & & $1.380(1.009-1.888)$ & \\
\hline PT_INR $>1.25$ & & $1.550(1.022-2.350)$ & & $1.590(1.202-2.103)$ \\
\hline $\mathrm{APTT}>40$ & & $2.101(1.393-3.170)$ & & \\
\hline
\end{tabular}

$A D L$ activities of daily living, $A L B$ serum albumin (mg/dl), $A L T$ alanine transaminase (IU/l), $A P T T$ activated partial thromboplastin time (s), $A S A$ American Society of Anesthesiologists, $A S T$ aspartate transaminase (IU/l), BMI body mass index $\left(\mathrm{kg} / \mathrm{m}^{2}\right), B S A$ body surface area $\left(\mathrm{m}^{2}\right), C O P D$ chronic obstructive pulmonary disease, $N a$ natrium $(\mathrm{mEq} / \mathrm{l}), C R P$ C-reactive protein $(\mathrm{mg} / \mathrm{dl}), e G F R$ estimated glomerular filtration rate $(<\mathrm{ml} /$ $\left.\mathrm{min} / 1.73 \mathrm{~m}^{3}\right), H C T$ hematocrit, $P C I$ percutaneous coronary intervention, $P L t$ platelets $\left(\times 10^{4} / \mu \mathrm{l}\right), P T$-INR prothrombin time-international normalized ratio, $P V D$ peripheral vascular disease, $W B C$ white blood cell count $\left(>10,000 / \mathrm{m}^{3}\right), 95 \% C I 95 \%$ confidence interval

$0.748(95 \% \mathrm{CI}, 0.712-0.783)$ for any systemic sepsis, $0.832(95 \% \mathrm{CI}, 0.789-0.875)$ for renal failure, 0.728 (95\% CI, 0.652-0.804) for cardiac events, 0.700 (95\% CI, 0.650-0.750) for blood transfusions over 5 units, 0.779 (95\% CI, 0.719-0.839) for CNS events, and 0.658 (95\% CI, 0.627-0.690) for anastomotic leakage (Fig. 2a-h). The calibration of the models showed how well we could predict the events based on the observed events in each 10 quantile subgroup (Supplemental Fig. 3a-d, e-h).

To determine whether the models predict potentially lethal morbidities regardless of the surgical approach, C-indices were calculated separately for patients who underwent laparoscopic gastrectomy and those treated by open gastrectomy using the 2011-2012 validation data set. The $\mathrm{C}$-indices for the morbidities in open distal gastrectomy and laparoscopic distal gastrectomy were 0.807 and 0.772 for unplanned intubation, 0.774 and 0.792 for pneumonia, 0.714 and 0.700 for any systemic sepsis, 0.842 and 0.810 for renal failure, 0.787 and 0.721 for cardiac events, 0.758 and 0.704 for blood transfusions over 5 units, 0.797 and 0.741 for CNS events, and 0.659 and 0.652 for anastomotic leakage, respectively (Supplemental Fig. 4). Thus, the relevance of the selected morbidities was similar between the two surgical approaches. Furthermore, the C-indices for each morbidity in the 2013 validation data set were 0.787 (95\% CI, 0.760-0.814) for unplanned intubation, 0.777 (95\% CI, 0.760-0.795) for pneumonia, 0.739 (95\% CI, 0.714-0.764) for any systemic sepsis, 0.816 (95\% CI, 0.787-0.845) for renal failure, 0.765 (95\% CI, 0.723-0.808) for cardiac events, 0.727 (95\% CI, 0.694-0.759) for blood transfusions over 5 units, 0.741 (95\% CI, 0.698-0.784) for CNS events, and 0.657 (95\% CI, 0.639-0.675) for anastomotic leakage (Supplemental Fig. 5a-h).

\section{Discussion}

The current study based on the NCD data constructed and validated the risk models with preoperative comorbidities that were designed to predict eight morbidities (unplanned intubation, pneumonia, systemic sepsis, renal failure, cardiac events, transfusions $>5$ units, CNS, events and anastomotic leakage) that were all highly associated with operative mortality after distal gastrectomy. This study used data from 65,906 patients registered during 2011 and 2012 and from 35,575 patients registered in 2013. The postoperative morbidity, 30-day mortality, and operative mortality observed in the current study were comparable to results from our previous report using NCD data from 33,917 cases collected in 2011 [17]. To our knowledge, this is the first nationwide study that has shown that preoperative factors can be used to predict morbidities correlated both with mortality and with other major morbidities.

We identified between 13 and 25 preoperative risk factors for each of the eight postoperative morbidities highly associated with mortality. Of these, male gender, older age, and poor ADL were most frequently selected independent risk factors for any morbidities. As it is sometimes difficult to appropriately treat these morbidities, it is important to be able to predict them so that they could be prevented. In case a patient is regarded as high risk, a surgeon could select more limited surgery or reduce the extent of lymph node dissection so as to suppress the surgical burden. Moreover, one could intensively treat and improve at least some of the preoperative risk factors for each morbidity instead of rushing into surgery. In addition, this study provided a method for comprehensive risk calculation to identify patients likely to need intensive perioperative care when receiving distal gastrectomy. 
a Unplanned intubation

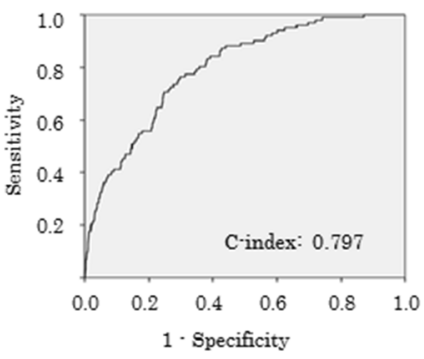

e Cardiac events

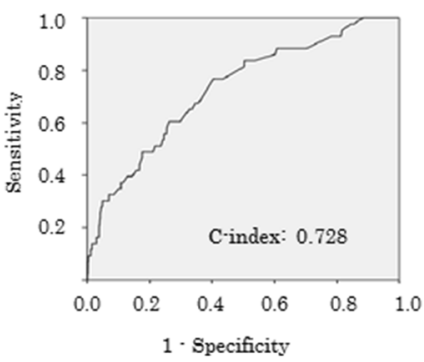

b Pneumonia

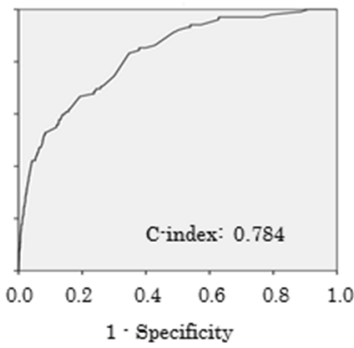

f Blood transfusion over 5 units

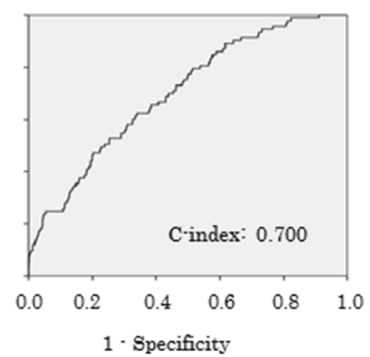

C Any systemic sepsis

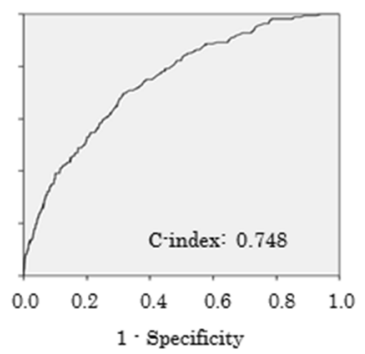

g CNS events

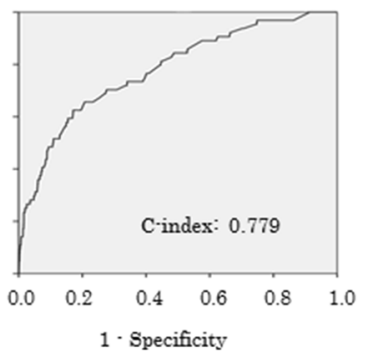

d Renal failure

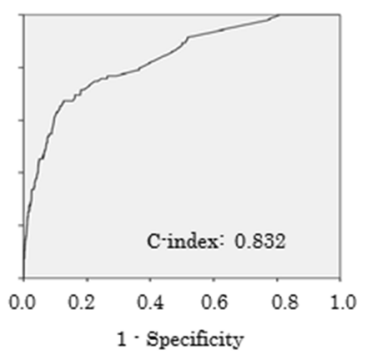

h Anastomotic leakage

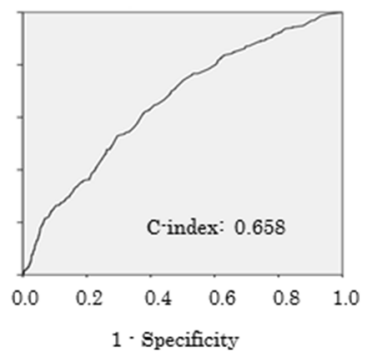

Fig. 2 ROC curves for eight events associated with mortality during distal gastrectomy for gastric cancer using the 2011-2012 validation data set from the Japanese NCD. C-indices $(95 \% \mathrm{CI})$ for each risk model were unplanned intubations, 0.797 (95 \% CI, 0.785-0.837) (a); pneumonia, 0.784 (95\% CI, 0.755-0.813) (b); any systemic sepsis,

Significant differences in terms of patient characteristics were observed between the patient groups treated by a different approach. We found that the general status of patients who underwent open distal gastrectomy was poor as compared to those in patients receiving laparoscopic distal gastrectomy. In the Japanese gastric cancer treatment guidelines, the indication for laparoscopic distal gastrectomy in general practice is confined to clinical stage I gastric cancer [21]. Therefore, advanced-stage gastric cancer has been more frequently treated by open surgery. However, the surgical approach (open or laparoscopic) did not show any difference in the $\mathrm{C}$-indices for each risk model. We can assume, therefore, that risk factors for each of the postoperative morbidities may be the same regardless of the surgical approach, and this risk model can be applied to all patients undergoing distal gastrectomy for gastric cancer.

Previous studies have reported various systems for predicting surgical risks. The physiological and operative severity score for the enumeration of mortality and morbidity (POSSUM) score [22], modified POSSUM [23], and the estimation of physiological ability and surgical stress (E-PASS) scoring system [24] have been reported to provide reliable predictive scores for mortality and morbidity. However, although these scoring systems predicted total morbidity, they used both preoperative and intraoperative
0.748 (95\% CI, 0.712-0.783) (c); renal failure, 0.832 (95\% CI, 0.789-0.875) (d); cardiac events, 0.728 (95\% CI, 0.652-0.804) (e); blood transfusions more than 5 units, 0.700 (95\% CI, 0.650-0.750) (f); CNS events, 0.779 (95\% CI, 0.719-0.839) (g); anastomotic leakage, 0.658 (95\% CI, 0.627-0.690) (h)

factors to predict postoperative morbidity and mortality. The strength of the risk prediction system proposed in the current study is that it relies solely on the preoperative risk factors. Furthermore, POSSUM and E-PASS are not specific for gastric surgery; some modifications are necessary.

The previous NCD study enabled the users to predict 30-day mortality and postoperative operative mortality inclusively by inserting preoperative factors into the formula on the NCD homepage [17]. In the near future, it will be possible to predict each morbidity after distal gastrectomy closely related with mortality in the same way based on this study.

Concerning the generalizability of the data clarified in this study, we shall have to admit that the results obtained may not be applicable to total gastrectomy cases and Western patients undergoing gastrectomies. Through independent analysis using the NCD data, another risk model to predict 30-day mortality and operative mortality was constructed for patients who underwent total gastrectomy [25]. Selected preoperative risk factors in that study were different from those identified in the current study, reflecting the difference in surgical stress, nutritional consequences, and mortality following the two types of gastrectomy. Similarly, patient characteristic and intraoperative factors in Western gastric cancer patients 
receiving distal gastrectomy may differ from these of Japanese patients. So, it is difficult to simply apply the current study outcomes to Western gastric cancer patients.

Validity of the results in the current study was robustly confirmed by the acceptable $\mathrm{C}$-indices observed in both the validation data set derived from the same time period and another independent data set acquired in 2013. This analysis conformed to the recent TRIPOD statement [20], which recommended using both internal and external validation studies for the transparent reporting of multivariable prediction models for individual prognosis or diagnosis. Moreover, the NCD database includes a large number of cases from all types of hospitals ranging from low-volume community hospitals to high-volume centers in Japan. Therefore, obtained risk models are considered applicable to various types of institutions throughout the country. Additionally, this study has some opportunities for further analysis. We have initially focused here on creating risk models using only preoperative variables. Future studies will be able to address other variables, such as intraoperative parameters, as well as data on tumor progression ( $\mathrm{T}$ and $\mathrm{N}$ stage), and the curability of surgery, which could also affect patient outcomes [13-15, 26]. The timing of these postoperative morbidities is also important to predict postoperative course, although we cannot confirm the timing of the each morbidity. By these additional analyses, more reliable risk models could be created.

In conclusion, we have identified predictive preoperative factors for eight major postoperative morbidities associated with mortality after distal gastrectomy using the Japanese NCD database. These models can help predict surgical outcomes and may be useful for making surgical decisions and comparing the quality of surgical outcomes in a risk-adjusted fashion.

\begin{abstract}
Acknowledgments The authors thank all the gastroenterological surgeons and data managers in Japan for participating in the NCD project and for their great efforts in entering data. We also thank Harushi Udagawa, M.D. Ph.D., Toshiaki Watanabe, M.D. Ph.D., Akira Tangoku, M.D. Ph.D., Michiaki Unno, M.D. Ph.D., and Akinobu Taketomi, M.D. Ph.D., who are the working members of the Japanese Society of Gastroenterological Surgery database committee. Mitsukazu Gotoh, who is one of the Japanese Society of Gastroenterological Surgery database committee, had full access to all the data in the study and takes responsibility for the integrity of the data and the accuracy of the data analysis.
\end{abstract}

\section{Compliance with ethical standards}

Conflicts of interest All authors had no potential conflicts of interest, including relevant financial interests, activities, relationships, and affiliations. The study was supported by a research grant from the Ministry of Health, Labor and Welfare, Japan.

Human rights statement and informed consent All procedures followed were in accordance with the ethical standards of the responsible committee on human experimentation (institutional and national) and with the Helsinki Declaration of 1964 and later versions. Informed consent or a substitute for it was obtained from all patients for being included in the study.

Animal studies This article does not contain any studies with human or animal subjects performed by any of the authors.

\section{References}

1. Cancer IAfRo. GLOBOCAN 2012: Estimated cancer incidence, mortality, and prevalence worldwide in 2012. Available at: http:// globocan.iarc.fr/Pages/fact_sheets_cancer.aspx. Accessed May 2015.

2. Ajani JA, Bentrem DJ, Besh S, D'Amico TA, Das P, Denlinger C, et al. Gastric cancer, version 2.2013: featured updates to the NCCN Guidelines. JNCCN. 2013;11:531-6.

3. Japanese Gastric Cancer Association. Japanese classification of gastric carcinoma: 3rd English edition. Gastric Cancer 2011;14:101-12.

4. Sierzega M, Kolodziejczyk P, Kulig J; Polish Gastric Cancer Study Group. Impact of anastomotic leakage on long-term survival after total gastrectomy for carcinoma of the stomach. Br J Surg. 2010;97:1035-42.

5. Migita K, Takayama T, Matsumoto S, Wakatsuki K, Enomoto K, Tanaka $\mathrm{T}$, et al. Risk factors for surgical site infections after elective gastrectomy. J Gastrointest Surg. 2012;16:1107-15.

6. Kim CS, Oak CY, Kim HY, Kang YU, Choi JS, Bae EH, et al. Incidence, predictive factors, and clinical outcomes of acute kidney injury after gastric surgery for gastric cancer. PLoS One. 2013;8:e82289.

7. Zhang J, Feng G, Yang Y, et al. Acute kidney injury after radical gastrectomy: a single center study. Int Urol Nephrol. 2014;46:973-7.

8. Inokuchi M, Kojima K, Kato K, Sugita H, Sugihara K. Risk factors for post-operative pulmonary complications after gastrectomy for gastric cancer. Surg Infect (Larchmt). 2014;15:314-21.

9. Mohri Y, Tonouchi H, Miki C, Kobayashi M, Kusunoki M; Mie Surgical Infection Research Group. Incidence and risk factors for hospital-acquired pneumonia after surgery for gastric cancer: results of prospective surveillance. World J Surg. 2008;32:1045-50.

10. Thompson DA, Makary MA, Dorman T, Pronovost PJ. Clinical and economic outcomes of hospital acquired pneumonia in intraabdominal surgery patients. Ann Surg. 2006;243:547-52.

11. Haga Y, Beppu T, Doi K, Nozawa F, Mugita N, Ikei S, et al. Systemic inflammatory response syndrome and organ dysfunction following gastrointestinal surgery. Crit Care Med. 1997;25:1994-2000.

12. Milgrom DP, Njoku VC, Fecher AM, Kilbane EM, Pitt HA. Unplanned intubation: when and why does this deadly complication occur? Surgery (St. Louis). 2013;154:376-83.

13. Kodera Y, Sasako M, Yamamoto S, Sano T, Nashimoto A, Kurita $\mathrm{A}$, et al. Identification of risk factors for the development of complications following extended and superextended lymphadenectomies for gastric cancer. Br J Surg. 2005;92:1103-9.

14. Bartlett EK, Meise C, Roses RE, Fraker DL, Kelz RR, Karakousis GC. Morbidity and mortality of cytoreduction with intraperitoneal chemotherapy: outcomes from the ACS NSQIP database. Ann Surg Oncol. 2014;21:1494-500.

15. Papenfuss WA, Kukar M, Oxenberg J, Attwood K, Nurkin S, Malhotra U, et al. Morbidity and mortality associated with gastrectomy for gastric cancer. Ann Surg Oncol. 2014;21:3008-14.

16. Etoh T, Katai H, Fukagawa T, Sano T, Oda I, Gotoda T, et al. Treatment of early gastric cancer in the elderly patient: results of EMR and gastrectomy at a national referral center in Japan. Gastrointest Endosc. 2005;62:868-71. 
17. Kurita N, Miyata H, Gotoh M, Shimada M, Imura S, Kimura W, et al. Risk model for distal gastrectomy when treating gastric cancer on the basis of data from 33,917 Japanese patients collected using a nationwide web-based data entry system. Ann Surg 2015;262(2):295-303

18. Miyata H, Gotoh M, Hashimoto H, Motomura N, Murakami A, Tomotaki A, et al. Challenges and prospects of a clinical database linked to the board certification system. Surg Today. 2014;44:1991-9.

19. Gotoh M, Miyata H, Hashimoto H, Wakabayashi G, Konno H, Miyakawa S, et al. National Clinical Database feedback implementation for quality improvement of cancer treatment in Japan: from good to great through transparency. Surgery Today 2016;46(1):38-47

20. Collins GS, Reitsma JB, Altman DG, Moons KG. Transparent reporting of a multivariable prediction model for individual prognosis or diagnosis (TRIPOD): the TRIPOD Statement. Br J Surg. 2015;102:148-58.

21. Japanese Gastric Cancer Association. Japanese gastric cancer treatment guidelines 2014 (ver. 4). Gastric Cancer. 2016;. doi:10. 1007/s10120-016-0622-4.
22. Luna A, Rebasa P, Navarro S, Montmany S, Coroleu D, Cabrol J, et al. An evaluation of morbidity and mortality in oncologic gastric surgery with the application of POSSUM, P-POSSUM, and O-POSSUM. World J Surg. 2009;33:1889-94.

23. Otsuka Y, Kunisaki C, Ono H, Yamada R, Matsuda G, Nomura M, et al. Modified POSSUM to predict postoperative morbidity following gastrectomy. Hepatogastroenterology. 2007;54:1142-5.

24. Ariake K, Ueno T, Takahashi M, Goto S, Sato S, Akada M, et al. E-PASS comprehensive risk score is a good predictor of postsurgical mortality from comorbid disease in elderly gastric cancer patients. J Surg Oncol. 2014;109:586-92.

25. Watanabe M, Miyata H, Gotoh M, Baba H, Kimura W, Tomita N, et al. Total gastrectomy risk model: data from 20,011 Japanese patients in a nationwide internet-based database. Ann Surg. 2014;260:1034-9.

26. Kim HH, Hyung WJ, Cho GS, Kim MC, Han SU, Kim W, et al. Morbidity and mortality of laparoscopic gastrectomy versus open gastrectomy for gastric cancer: an interim report-a phase III multicenter, prospective, randomized trial (KLASS Trial). Ann Surg. 2010;251:417-20. 